\title{
Monitoring of Serum Prolactin in Pediatric Patients with Cystic Fibrosis Who Are Receiving Domperidone
}

\author{
Eva Cho, Sharon Ho, Patricia Gerber, and A George F Davidson
}

\begin{abstract}
Background: Since 2003, it has been routine practice at Children's and Women's Health Centre of British Columbia to monitor serum levels of prolactin in pediatric patients with cystic fibrosis who are receiving domperidone. Although a pharmacologic relationship between domperidone and prolactin has been documented in the literature, there is no information about routine monitoring of prolactin, and guidance on interpretation of prolactin values is lacking.

Objectives: To characterize how prolactin levels were being used in monitoring patients with cystic fibrosis who were receiving domperidone therapy at this institution, to evaluate the need for this practice, and to formulate recommendations accordingly.

Methods: A chart review was conducted for pediatric patients with cystic fibrosis who had been receiving domperidone therapy and whose serum prolactin levels had been monitored between June 1, 2001, and October 1, 2005.

Results: A total of 219 samples had been drawn, from 49 patients, for determination of prolactin level. Of these, $100(45.7 \%)$ were above the normal range. Of the values above the normal range, $86(86 \%)$ led to no dosage adjustment of domperidone and $14(14 \%)$ led to either a decrease in dose or discontinuation of therapy. None of the elevated prolactin levels were associated with supratherapeutic doses of domperidone.

Conclusion: The role of routine monitoring of prolactin in this patient population requires further study. In particular, more information is needed about prolactin levels in pediatric patients and the relationship of prolactin level to domperidone dose.
\end{abstract}

Key words: serum prolactin level, domperidone, pediatric, cystic fibrosis

Can J Hosp Pharm 2009;62(2):119-126

\section{RÉSUMÉ}

Contexte : Depuis 2003, au Children's and Women's Health Centre of British Columbia, on procède systématiquement au dosage des concentrations sériques de prolactine chez les patients en pédiatrie atteints de fibrose kystique qui reçoivent de la dompéridone. Bien que la littérature fasse état d'un lien pharmacologique entre la dompéridone et la prolactine, il n'y a aucune information sur le dosage systématique de la prolactine, et on note l'absence de lignes directrices sur l'interprétation des taux de prolactine.

Objectifs : Caractériser comment les taux de prolactine ont été utilisés pour faire le suivi des patients atteints de fibrose kystique qui recevaient de la dompéridone à cet établissement, évaluer le besoin de recourir à une telle pratique et formuler des recommandations, le cas échéant.

Méthodes : Une analyse des dossiers médicaux des patients en pédiatrie atteints de fibrose kystique qui recevaient de la dompéridone et dont les taux sériques de prolactine ont été surveillés entre le premier juin 2001 et le premier octobre 2005 a été effectuée.

Résultats : Au total, 219 échantillons ont été prélevés de 49 patients dans le but de déterminer les taux de prolactine. De ceux-ci, 100 (46\%) présentaient des taux au-dessus de la fourchette des valeurs normales. Pour 86 (86\%) de ces échantillons avec des valeurs au-dessus de la normale, aucun ajustement de la dose de dompéridone n’a été effectué, mais une diminution de la dose ou un arrêt du traitement a été effectué pour les 14 autres $(14 \%)$. Aucun des taux élevés de prolactine n’a été associé à des doses de dompéridone suprathérapeutiques.

Conclusion : Le rôle du dosage systématique de la prolactine dans cette population de patient doit faire l'objet d'autres études. Plus particulièrement, il y a un besoin de plus d'information sur les taux de prolactine chez les patients en pédiatrie et sur le lien entre le taux de prolactine et la dose de dompéridone.

Mots clés : taux sériques de prolactine, dompéridone, pédiatrie, fibrose kystique

[Traduction par l'éditeur] 


\section{INTRODUCTION}

$\mathrm{D}$ omperidone, a prokinetic and antiemetic agent, is a peripheral dopamine,-receptor antagonist with effects in the upper gastrointestinal tract and the chemoreceptor trigger zone. Domperidone antagonizes the effect of dopamine on the smooth muscle, including the gastric and esophageal sphincters, which results in increased smooth-muscle contraction in the stomach and duodenum and hence increased gastrointestinal motility. Antagonism of dopamine action at the chemoreceptor trigger zone results in antiemesis. At the pituitary level, antagonism of dopamine leads to prolactin release, and as such, domperidone has been reported to cause gynecomastia, galactorrhea, oligomenorrhea, amenorrhea, infertility, decreased libido, hirsutism, and acne, all of which are manifestations of hyperprolactinemia. ${ }^{1}$

Pediatric patients with cystic fibrosis account for a large proportion of domperidone users because of the high incidence of gastroesophageal reflux disease (GERD) in this population (estimated at between $25 \%$ and $81 \%$ ). ${ }^{2}$ Prokinetic agents such as domperidone are frequently prescribed to alleviate GERDrelated symptoms and to target the delay in gastric emptying that has been noted in this population. ${ }^{3}$

At the Children's and Women's Health Centre of British Columbia, GERD therapy for children with cystic fibrosis typically involves a histamine ${ }_{2}$-antagonist (e.g., ranitidine) or a proton pump inhibitor (e.g., omeprazole). Domperidone is prescribed if these therapies are ineffective or not tolerated. At the time of writing, domperidone was prescribed for the alleviation of GERD symptoms for about $40 \%$ of patients with cystic fibrosis at this institution. As of late 2005, use of the drug exceeded 83600 tablets per year, an increase from 14600 tablets per year in 2001. This increase was related to withdrawal of the prokinetic agent cisapride from the Canadian market in August of 2000.

In March 2003, the cystic fibrosis medical team was involved in caring for a 15-year-old female with cystic fibrosis who presented with amenorrhea and in whom prolactinoma was subsequently diagnosed. At the time, she was receiving multiple drug therapies, including domperidone $0.9 \mathrm{mg} / \mathrm{kg}$ daily, for the management of her cystic fibrosis. The physicians involved in her care, including the cystic fibrosis and endocrinology medical teams, suspected that the prolactinoma might be associated with the use of domperidone. Domperidone therapy was therefore discontinued, and serial samples were drawn for determination of serum prolactin levels to monitor her progress. At the time of diagnosis of the prolactinoma, the patient's prolactin level was elevated, at $83.6 \mu \mathrm{g} / \mathrm{L}$ (normal range 3.3-26.7 $\mu \mathrm{g} / \mathrm{L}$ ); it decreased to a normal value of $11.6 \mu \mathrm{g} / \mathrm{L}$ within 2 days of discontinuation of domperidone therapy. Suspecting a direct, clinically significant relationship between the elevated prolactin level and domperidone, the cystic fibrosis team began to routinely monitor prolactin levels in all children with cystic fibrosis who were receiving this drug.

No specific guidelines are in place at this institution for monitoring prolactin or interpreting prolactin values in patients receiving domperidone therapy. A thorough literature search (using MEDLINE, EMBASE, PubMed, the Cochrane Database of Systematic Reviews, and Google databases) revealed no published guidelines for interpreting prolactin values in this population nor any evidence supporting this practice. In view of this lack of evidence and apparent inconsistency in the timing, frequency, and clinical interpretation of prolactin levels in relation to domperidone dosing, as well as the associated costs ( $\$ 30.76$ for a single prolactin determination), a review of this practice was undertaken.

The purpose of this chart review was to assess the use of prolactin monitoring in children with cystic fibrosis who were receiving domperidone therapy. The specific objectives were to characterize how prolactin values were used in monitoring these patients, to evaluate the appropriateness of this practice, and to formulate recommendations accordingly.

\section{METHODS}

A chart review was conducted for pediatric patients with cystic fibrosis who were admitted to the Children's and Women's Health Centre of British Columbia between June 1, 2001, and October 1, 2005. This study period was selected to capture data before and after the previously described case that had precipitated routine monitoring of prolactin in patients with cystic fibrosis who were receiving domperidone. Patients who were receiving domperidone and for whom prolactin level had been measured at least once were included in the chart review. Patients who did not have cystic fibrosis were excluded because only patients who had this disease and were receiving domperidone therapy routinely underwent prolactin monitoring at this institution. A list of all inpatients for whom domperidone therapy had been prescribed during the study period was obtained from records in the Pharmacy Department, and a list of all patients who had had samples drawn for determination of prolactin level was obtained from the Department of Pathology and Laboratory Medicine. Only inpatients were included, as laboratory records from outside the institution (especially for patients referred from outside the hospital's immediate geographic location) were not readily available for review. The 2 lists were cross-referenced to generate a final list of patients whose charts were retrieved for review.

Data collected in the chart review included demographic characteristics, medication history, domperidone doses, frequency of administration, duration of therapy, serum prolactin values, and the times at which the samples were 
drawn for serum prolactin determination. Data reflecting the efficacy of domperidone therapy (e.g., gastric emptying scans, reflux studies, severity of symptoms), any reported toxic effects of domperidone (e.g., signs or symptoms associated with abnormal serum prolactin levels), and patients' compliance with the regimen were also captured.

All measurements of serum prolactin were obtained using the Beckman Access Immunoassay System (Beckman Instruments, Inc, Fullerton, California), a paramagneticparticle chemiluminescent immunoassay system that quantifies serum prolactin levels within the range of 0.25 to $200 \mu \mathrm{g} / \mathrm{L}$. All prolactin values were compared with the laboratory's normal reference ranges as follows: $2.6-13.1 \mu \mathrm{g} / \mathrm{L}$ for males and 3.3-26.7 $\mu \mathrm{g} / \mathrm{L}$ for premenopausal females.

\section{Outcome Measures}

The way in which prolactin values were used for monitoring was characterized by calculating the percentage of patients with elevated prolactin levels and the percentage of elevated values that resulted in dosage adjustment, and by evaluating the results for dual samples drawn from patients for whom withinrange prolactin levels had raised questions about patient compliance. Appropriateness of therapy was evaluated by considering how the prolactin values had been interpreted.

\section{Data Analysis}

Medians and ranges were calculated for nonparametric data.

\section{RESULTS}

Records from the Pharmacy Department and the Pathology and Laboratory Medicine Department identified 71 patients who had received domperidone therapy and who had undergone monitoring of serum prolactin levels between June 1, 2001, and October 1, 2005. Of these, 22 patients were excluded because they did not have a diagnosis of cystic fibrosis. A total of 49 pediatric patients with cystic fibrosis, 26 females and 23 males, were included in this chart review.

The median age at initiation of domperidone therapy was 8.5 years (range 1 month to 18 years). The median dose of domperidone was $1.42 \mathrm{mg} / \mathrm{kg}$ per day (range $0.45-3.41 \mathrm{mg} / \mathrm{kg}$ per day) (Figure 1). Dosing guidelines at this institution during the study period recommended a dosage of $1.2-2.4 \mathrm{mg} / \mathrm{kg}$ per day for children.

A total of 219 samples for determination of prolactin levels were drawn from the 49 study patients during a total of 106 hospital admissions and 88 visits to the cystic fibrosis clinic. No prolactin levels had been measured before March

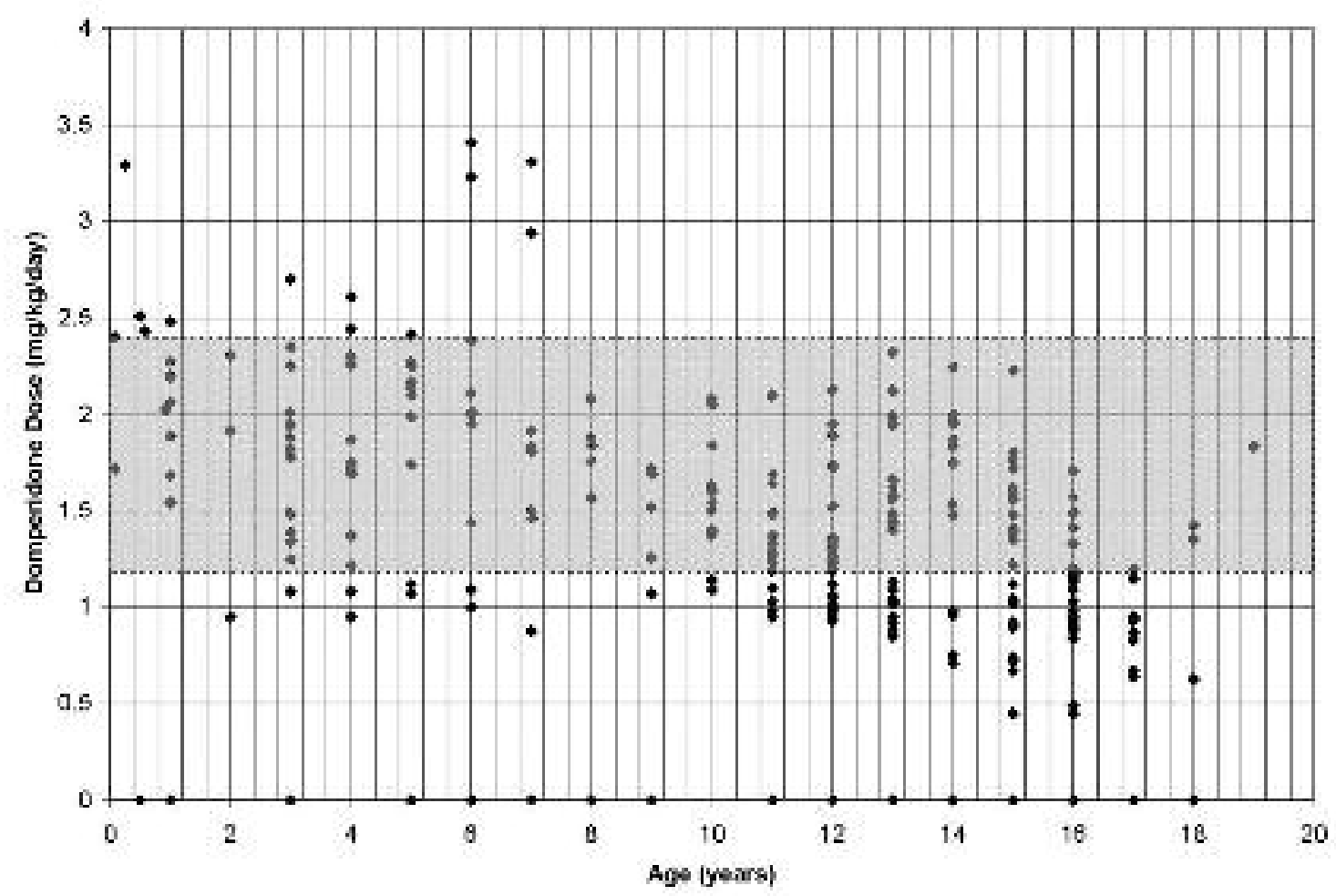

Figure 1. Domperidone dosage in relation to age for 49 children with cystic fibrosis who underwent prolactin monitoring. Shaded area indicates recommended dosage at this institution at the time of the study. 


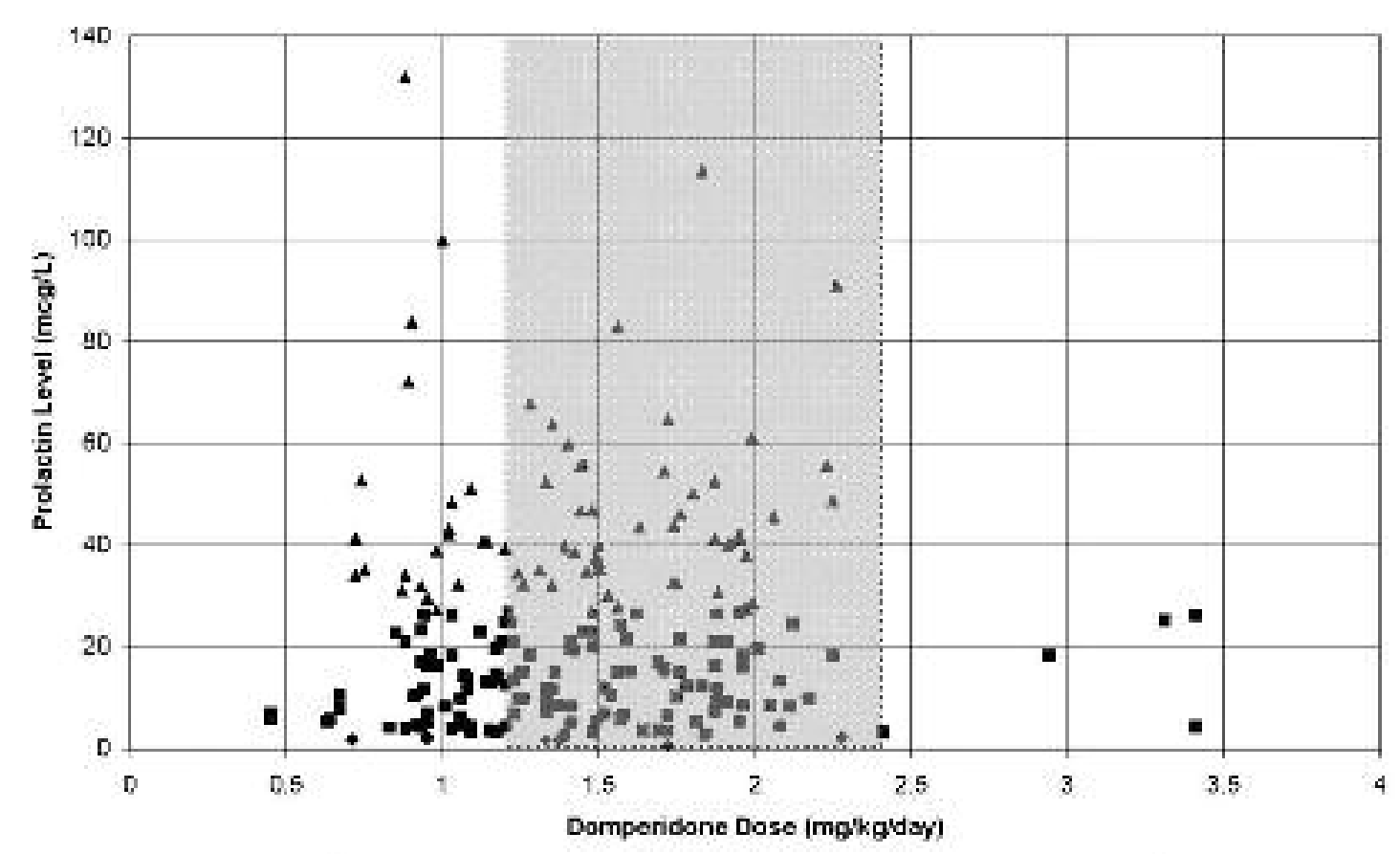

- Below Normal Resge a Within Nomal Renge a Above Normel Range

Figure 2. Prolactin levels in relation to domperidone dose in the 49 study patients. Shaded area indicates recommended dosage at this institution at the time of the study.

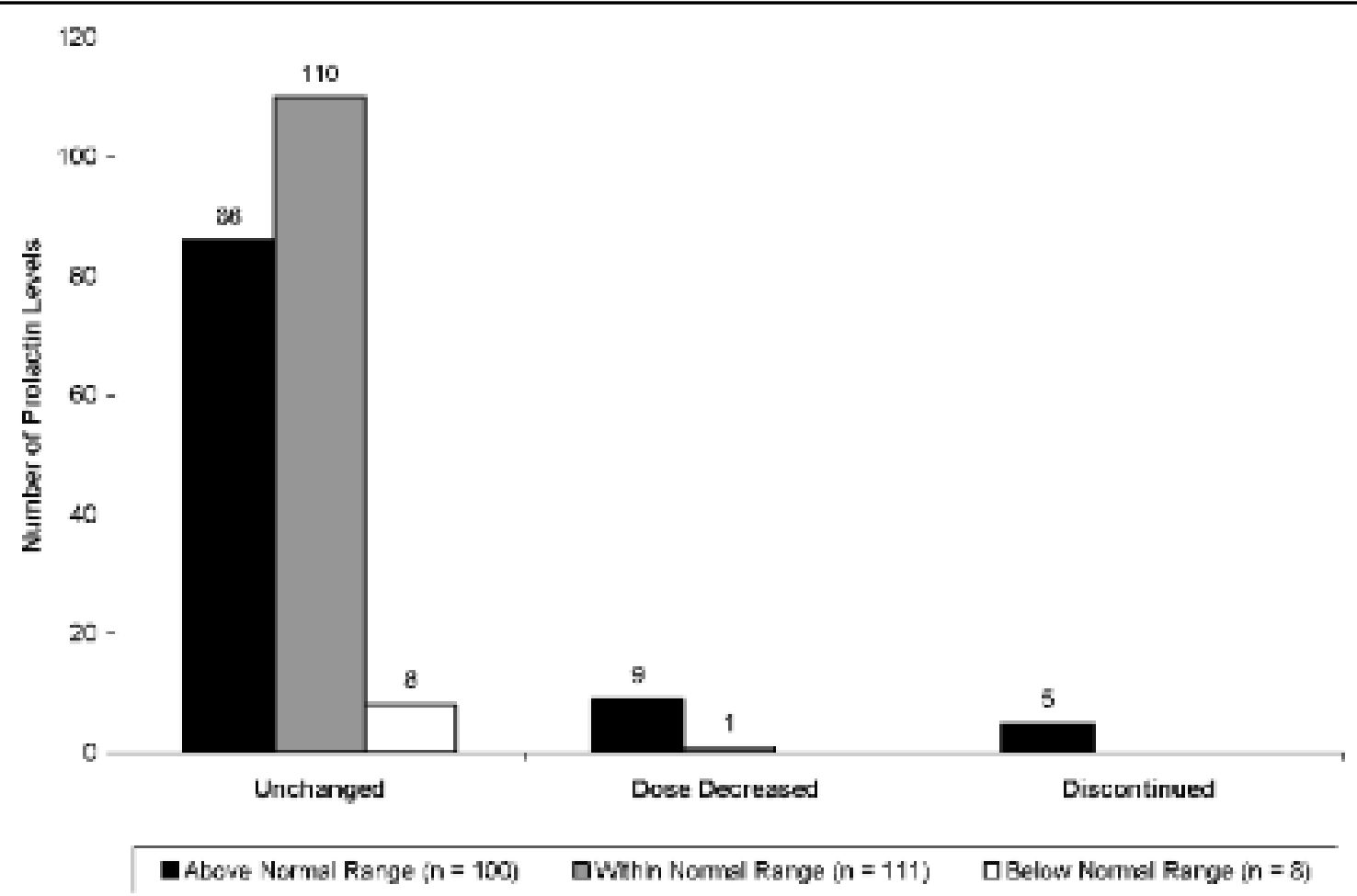

Figure 3. Adjustments of domperidone dosage based on interpretation of prolactin values. 
Table 1. Individual Domperidone Doses and Prolactin Levels that Led to a Decrease in Domperidone Dose

\begin{tabular}{lccc} 
Patient & Sex & $\begin{array}{c}\text { Domperidone Dose* } \\
(\mathbf{m g} / \mathbf{k g} \text { per day) }\end{array}$ & $\begin{array}{c}\text { Prolactin Levelt } \\
(\boldsymbol{\mu} \mathbf{g} / \mathrm{L})\end{array}$ \\
\hline 1 & $\mathrm{~F}$ & 1.48 & 47.0 \\
2 & $\mathrm{~F}$ & 1.56 & 82.8 \\
3 & $\mathrm{~F}$ & 1.72 & 64.7 \\
4 & $\mathrm{~F}$ & 1.80 & 50.1 \\
5 & $\mathrm{M}$ & 0.74 & 55.7 \\
6 & $\mathrm{M}$ & 1.74 & 43.9 \\
7 & $\mathrm{M}$ & 1.95 & 42.2 \\
8 & $\mathrm{M}$ & 1.99 & 61.1 \\
9 & $\mathrm{M}$ & 2.26 & 91.1 \\
\hline
\end{tabular}

* Recommended range for children: $1.2-2.4 \mathrm{mg} / \mathrm{kg}$ per day. ${ }^{4}$ †Normal range 3.3-26.7 $\mu \mathrm{g} / \mathrm{L}$ for premenopausal females, 2.6-13.1 $\mu \mathrm{g} / \mathrm{L}$ for males.

Table 2. Individual Domperidone Doses and Prolactin Levels that Resulted in Discontinuation of Domperidone Therapy

\begin{tabular}{lccc} 
Patient & Sex & $\begin{array}{c}\text { Domperidone Dose* } \\
(\mathbf{m g} / \mathbf{k g} \text { per day) }\end{array}$ & $\begin{array}{c}\text { Prolactin Levelt } \\
(\boldsymbol{\mu} \mathbf{g} / \mathbf{L})\end{array}$ \\
\hline 4 & $\mathrm{~F}$ & 1.35 & 63.7 \\
10 & $\mathrm{~F}$ & 0.88 & 131.9 \\
11 & $\mathrm{~F}$ & 0.90 & 83.6 \\
12 & $\mathrm{~F}$ & 1.40 & 59.8 \\
8 & $\mathrm{M}$ & 1.00 & 99.8
\end{tabular}

* Recommended range for children: $1.2-2.4 \mathrm{mg} / \mathrm{kg}$ per day. ${ }^{4}$ †Normal range 3.3-26.7 $\mu \mathrm{g} / \mathrm{L}$ for premenopausal females, $2.6-13.1 \mu \mathrm{g} / \mathrm{L}$ for males.

2003, when the previously described case of hyperprolactinemia resulting in amenorrhea and development of a prolactinoma had been reported.

Of the 49 study patients, 39 (80\%), consisting of 20 males and 19 females, had a record of at least one elevated prolactin value. All of these patients had been receiving domperidone as outpatient therapy before admission, and baseline prolactin levels had not been measured before the start of therapy. Of the 219 prolactin values reported, $100(45.7 \%)$ were above the normal range, $111(50.7 \%)$ were within the normal range, and $8(3.7 \%)$ were below the normal range. There appeared to be no relationship between the patients' domperidone doses and the measured prolactin levels (Figure 2). The median domperidone dose associated with prolactin values in the normal range was $1.24 \mathrm{mg} / \mathrm{kg}$ per day (range $0.45-3.41 \mathrm{mg} / \mathrm{kg}$ per day), and the median dose associated with elevated prolactin values was $1.43 \mathrm{mg} / \mathrm{kg}$ per day (range $0.72-2.26$ $\mathrm{mg} / \mathrm{kg}$ per day). In fact, none of the elevated prolactin values resulted from supratherapeutic domperidone doses.

To determine if the measured prolactin level influenced domperidone therapy, data reflecting whether the domperidone dose had been changed as a result of the prolactin level were recorded from the charts. Of the 100 values above the normal range, 86 (86\%) resulted in no dosage adjustments, $9(9 \%)$ resulted in a dosage decrease, and $5(5 \%)$ resulted in discontinuation of domperidone therapy (Figure 3). The prolactin levels resulting in a decrease in domperidone dose ranged from 42.2 to $91.1 \mu \mathrm{g} / \mathrm{L}$ (Table 1), and those resulting in discontinuation of therapy ranged from 59.8 to $131.9 \mu \mathrm{g} / \mathrm{L}$ (Table 2). The patients had been receiving domperidone doses ranging from 0.74 to $2.26 \mathrm{mg} / \mathrm{kg}$ per day and from 0.88 to $1.40 \mathrm{mg} / \mathrm{kg}$ per day, respectively. For the 9 instances in which an elevated prolactin value resulted in a decrease in domperidone dose, prolactin levels were also measured subsequent to the dosage decrease. The prolactin level rose in 3 cases and declined in 6 cases, but in 5 of the 6 latter cases, prolactin was still above the laboratory reference range. For the 86 cases in which elevated prolactin level resulted in no dosage adjustment, the prolactin values ranged from 13.2 to $72.2 \mu \mathrm{g} / \mathrm{L}$ in association with domperidone doses ranging from 0.72 to $2.25 \mathrm{mg} / \mathrm{kg}$ per day.

Prolactin levels are known to fluctuate during the day, with peak production during sleep and lowest production occurring at mid-afternoon. ${ }^{5}$ The time at which samples were drawn for prolactin determination varied greatly both between patients and within the same patient, with 137 (62.6\%) of the 219 samples being drawn in the morning (median prolactin level $19.6 \mu \mathrm{g} / \mathrm{L}$, range $0.9-99.8 \mu \mathrm{g} / \mathrm{L}$ ) and $82(37.4 \%)$ being drawn in the evening (median prolactin level $15.0 \mu \mathrm{g} / \mathrm{L}$, range $0.7-131.9 \mu \mathrm{g} / \mathrm{L}$ ). Given this variability and the diurnal pattern of prolactin production, domperidone dose might not have been the only factor influencing the measured values of prolactin.

The cystic fibrosis team considered prolactin levels below or at the lower limit of the normal reference range to be suggestive of noncompliance with therapy. In 15 (31\%) of the 49 patients, a total of 17 prolactin values (median $5.9 \mu \mathrm{g} / \mathrm{L}$, range $2.3-16.1 \mu \mathrm{g} / \mathrm{L}$ ) were deemed suggestive of noncompliance. Of the 106 hospital admissions, 25 (23.6\%) had records of 2 measurements of prolactin level, one at admission and one before anticipated discharge (after a 2-week hospital stay). For 23 of these patient admissions, the domperidone dosage remained the same throughout the hospital stay. In 20 (87\%) of these 23 cases, the prolactin level increased from a median of $10.9 \mu \mathrm{g} / \mathrm{L}$ at admission (range 3.3-35.5 $\mu \mathrm{g} / \mathrm{L}$ ) to a median of $29.5 \mu \mathrm{g} / \mathrm{L}$ before discharge (range 8.3-82.8 $\mu \mathrm{g} / \mathrm{L}$ ); in the other $3(13 \%)$ cases, the prolactin level decreased from a median of $39.4 \mu \mathrm{g} / \mathrm{L}$ at admission (range $16.3-41.4 \mu \mathrm{g} / \mathrm{L}$ ) to a median of $24.9 \mu \mathrm{g} / \mathrm{L}$ before discharge (range 7.0-34.2 $\mu \mathrm{g} / \mathrm{L}$ ). For 1 of the other 2 admissions with dual prolactin measurements (at admission and before discharge), the domperidone dosage was decreased because the initial prolactin level was elevated, at $50.1 \mu \mathrm{g} / \mathrm{L}$; however, even with the lower dosage, the subsequent 
prolactin level was higher, at $63.7 \mu \mathrm{g} / \mathrm{L}$. In the other case (the patient with amenorrhea and prolactinoma, described above), the domperidone was discontinued and the prolactin level declined.

Among these 25 admissions, 4 female patients were questioned about compliance because the admission prolactin value was within the normal range (median $7.0 \mu \mathrm{g} / \mathrm{L}$, range $4.4-12.4 \mu \mathrm{g} / \mathrm{L}$ ). For all 4 of these patients, prolactin level increased by the time of discharge, although it remained within the normal range (median $13.0 \mu \mathrm{g} / \mathrm{L}$, range 11.9 $26.3 \mu \mathrm{g} / \mathrm{L}$ ). There were 16 other admissions for which poor compliance may have been considered, given that prolactin levels were checked on admission and before discharge, although the patients were not specifically questioned. In these 16 cases, prolactin level increased during the hospital stay, from a median of $13.6 \mu \mathrm{g} / \mathrm{L}$ (range 3.3-35.5 $\mu \mathrm{g} / \mathrm{L}$ ) at admission to a median of $37.8 \mu \mathrm{g} / \mathrm{L}$ (range $8.3-82.8 \mu \mathrm{g} / \mathrm{L}$ ).

With the exception of the previously described patient with amenorrhea and prolactinoma, who was treated in 2003 and whose experience precipitated the routine measurement of prolactin levels, no reports of hyperprolactinemia-related side effects directly attributable to domperidone therapy were noted in the study population.

This chart review revealed 2 cases of amenorrhea in female patients 16 and 17 years of age. The 16-year-old patient was receiving medroxyprogesterone acetate by injection concurrently with domperidone therapy, and the 17-year-old patient was recovering from gastrointestinal bleeding. The prolactin level for these patients when amenorrhea was reported was $38.9 \mu \mathrm{g} / \mathrm{L}$ and $3.9 \mu \mathrm{g} / \mathrm{L}$, respectively. Both cases of amenorrhea were deemed unrelated to domperidone therapy.

The chart review also revealed 2 reports of delayed puberty. Domperidone therapy was discontinued for a 13-year-old girl whose measured serum prolactin level was elevated, at $131.9 \mu \mathrm{g} / \mathrm{L}$, while she was receiving domperidone $0.88 \mathrm{mg} / \mathrm{kg}$ per day. It was unclear whether the elevated prolactin had contributed to this patient's delayed puberty. The second patient was a 14-year-old girl whose serum prolactin level was $27.3 \mu \mathrm{g} / \mathrm{L}$ while she was receiving a low dose of domperidone; in this patient, delayed puberty was attributed to a family history of late menarche.

\section{DISCUSSION}

Although the literature confirms that domperidone therapy is associated with increases in serum prolactin levels and that symptoms of hyperprolactinemia have been reported as a result of using this drug, there is inconsistency with regard to the relationship between dosage or duration of therapy and prolactin level. ${ }^{1,67}$ Furthermore, there is no apparent relationship between serum prolactin level and the severity of symptoms associated with hyperprolactinemia.?
A thorough literature search revealed no guidelines for monitoring prolactin. Furthermore, manufacturers of domperidone do not suggest, or provide guidance on, routine prolactin monitoring for patients receiving this drug. A literature search for pediatric reference ranges for prolactin revealed great variability, depending on the patient population and the assay used to determine serum prolactin. Reference ranges were further categorized by age, sex, growth percentiles, and Tanner staging, ${ }^{8-11}$ all of which might have influenced the measured prolactin levels in the current study.

Case reports of adverse effects associated with domperidone therapy were also identified in the literature search. Nipple tenderness, gynecomastia, galactorrhea, and erectile dysfunction have been reported in adults receiving domperidone for the treatment of gastrointestinal symptoms. ${ }^{712-15}$ Among pediatric patients, there have been reports of domperidone-associated extrapyramidal dysfunction, oculogyric crisis, galactorrhea, and gynecomastia. ${ }^{16-19}$

This chart review appears to be the first study to report the monitoring of serum prolactin levels in pediatric patients who had cystic fibrosis and were receiving domperidone therapy. This practice does not appear to be employed for pediatric patients being treated with domperidone in the absence of cystic fibrosis, either at the Children's and Women's Health Centre of British Columbia or at other Canadian pediatric hospitals.

This study revealed that physicians considered patient reports of GERD symptoms and the results of gastric reflux scanning and gastric emptying studies in assessing the efficacy of a patient's GERD regimen and determining whether to alter therapy. Although prolactin levels did not assist physicians in monitoring the efficacy of domperidone therapy, they were nonetheless a factor in guiding dosage, specifically for decreasing domperidone dose in cases of elevated prolactin levels, with a view to preventing symptoms of hyperprolactinemia. However, baseline serum prolactin levels were not checked before the start of domperidone therapy in any of the patients in this study, which might have affected interpretation of the data and subsequent therapy. At times, the prolactin value was also used as an indicator of compliance. Four of the patients in this study were questioned about compliance and underwent prolactin monitoring on admission and before discharge. On the assumption that patients would be compliant with therapy while in hospital, the prolactin level might be expected to increase, and this trend was indeed observed, although values remained within the reference range. This finding supports the hypothesis that low levels may indicate poor compliance. However, prolactin levels may not be elevated above the normal reference range while a patient is receiving domperidone, so a single low prolactin value cannot be taken as proof of noncompliance. Paired measurements, obtained at the start and end of 
the hospital stay, may constitute a better indicator, but further investigation is warranted, as the prolactin level may unexpectedly be lower at discharge than admission.

In keeping with the results of the literature search, ${ }^{1,6}$ no apparent relationship was observed between domperidone dose and prolactin level. The domperidone doses that the patients were receiving when their prolactin was elevated were all below or within the recommended dosage range of $1.2-2.4 \mathrm{mg} / \mathrm{kg}$ per day.

Only $14 \%$ of the elevated prolactin values led to a decrease in domperidone dose or discontinuation of therapy. The inconsistency in therapeutic adjustment for patients with elevated prolactin suggests inconsistency in interpretation of these data or other unspecified factors affecting such decisions.

Except for the case of prolactinoma described above, there were no other reports of hyperprolactinemia symptoms directly attributed to domperidone therapy. In this study population, the highest prolactin level recorded was $131.9 \mu \mathrm{g} / \mathrm{L}$, with no adverse effects attributed to hyperprolactinemia. The patient was a 13-year-old female who had not reached menarche and who was receiving a subtherapeutic dose of domperidone at the time. Although the patient was asymptomatic, the domperidone was discontinued as a result of this prolactin result. Symptoms of hyperprolactinemia were not recorded for any of the other 48 patients, but because this was not a prospective trial designed to elucidate such symptoms, their absence cannot be stated with certainty.

This chart review revealed much variability in the timing of prolactin measurement, both within and between patients. In addition to the known diurnal fluctuation in prolactin release, prolactin levels may be altered by factors such as stress, eating, and exercise. ${ }^{5}$ As such, it is important to consider these factors when measuring and interpreting prolactin levels. In addition, reference prolactin levels at the authors' institution were derived primarily from adult values. Given the great variability in pediatric reference ranges in the literature, it would be useful to define pediatric reference ranges for specific institutions to help in interpreting measured values.

The findings reported here, as well as the apparent lack of a relationship between domperidone dose and prolactin level, suggest that it may be inappropriate to alter domperidone therapy on the basis of elevated prolactin level alone. For therapeutic drug monitoring of aminoglycosides, for example, a patient's serum drug levels can be monitored and the dose adjusted according to pharmacokinetic parameters estimated for that particular patient. In contrast, it is not clear how a domperidone dosage adjustment will affect a patient's prolactin level or if elevated prolactin will result in symptoms of hyperprolactinemia. Further research is needed to determine if there is a dose-response relationship between domperidone and prolactin levels and if there is a relationship between prolactin levels and symptoms of hyperprolactinemia. The question of whether high prolactin levels indicate toxicity needs further exploration through prospective trials and specific objective measures of potential toxic effects. Until such questions are answered, the measurement of prolactin levels will remain of limited use in adjusting domperidone dosage.

The possible use of prolactin levels as an indicator of patient compliance deserves further investigation. The observation of low prolactin levels at the start of a hospital stay associated with higher levels at the end of the hospital stay is consistent with the suggestion that the initial levels reflect poor compliance. However, more data are needed regarding the variability of serum levels of prolactin and the factors contributing to this variation.

This study had some limitations. First, it was a retrospective study in a small sample of patients. Data were based on a review of medical records, which might not have fully captured the decision-making process related to interpreting prolactin values. Second, this review was not designed to determine whether a dose-response relationship exists between domperidone and prolactin level. The literature evidence for such a relationship is mixed. Third, patients' compliance with their domperidone regimen outside of the hospital stay was unknown. Finally, baseline prolactin was not determined before the start of domperidone therapy, and samples for prolactin monitoring were drawn at different times of the day, which may have contributed to the observed fluctuation of levels.

This study has brought to light the difficulties in interpreting prolactin values and the need for more information before the true role of serum prolactin in monitoring domperidone therapy and evaluating patients' compliance can be determined.

\section{References}

1. Barone J. Domperidone: a peripherally acting dopamine2-receptor antagonist. Ann Pharmacother 1999;33(4):429-440.

2. Brodzicki J, Trawinska-Bartnicka M, Korzon M. Frequency, consequences and pharmacological treatment of gastroesophageal reflux in children with cystic fibrosis. Med Sci Monit 2002;8(7):CR529-CR537.

3. Schappi MG, Roulet M, Rochat T, Belli DC. Electrogastrography reveals post-prandial gastric dysmotility in children with cystic fibrosis. J Pediatr Gastroenterol Nutr 2004;39(3):253-256.

4. Esau R, editor. 2002/2003 pediatric drug dosage guidelines. Vancouver (BC): British Columbia's Children's Hospital; 2002.

5. Waseem M, Granti S, Gernsheimer J. Index of suspicion. Pediatr Rev 2004;25:68-73.

6. Prakash A, Wagstaff AJ. Domperidone-a review of its use in diabetic gastropathy. Drugs 1998;56:429-445.

7. Swift T. Galactorrhea-a side effect of domperidone? HSC Winnipeg Drug Info 1997;19(4):3.

8. Elmlinger MW, Kuhnel W, Ranke MB. Reference ranges for serum concentrations of lutropin (LH), follitropin (FSH), estradiol (E2), prolactin, progesterone, sex hormone-binding globulin (SHBG), dehydroepiandrosterone sulfate (DHEAS), cortisol and ferritin in neonates, children and young adults. Clin Chem Lab Med 2002;40(11):1151-1160.

9. Gassler N, Peuschel T, Pankau R. Pediatric reference values of estradiol, testosterone, lutropin, follitropin, and prolactin. Clin Lab 2000; 46(11-12):553-560. 
10. Soldin SJ, Morales A, Albalos F, Lenherr S, Rifai N. Pediatric reference ranges on the Abbott IMx for $\mathrm{FSH}, \mathrm{LH}$, prolactin, TSH, $\mathrm{T}_{4}, \mathrm{~T}_{3}$, free $\mathrm{T}_{4}$, free $\mathrm{T}_{3}$, T-uptake, IgE, and ferritin. Clin Biochem 1995;28(6): 603-606.

11. Wiedemann G, Jonetz-Mentzel L. Establishment of reference ranges for prolactin in neonates, infants, children and adolescents. Eur J Clin Chem Clin Biochem 1993;31(7):447-451.

12. Soykan I, Sarosiek I, Snifflett J, Wooten GF, McCallum RW. Effect of chronic oral domperidone therapy on gastrointestinal symptoms and gastric emptying in patients with Parkinson's disease. Mov Disord 1997;12(6):952-957.

13. Soykan I, Sarosiek I, McCallum RW. The effect of chronic oral domperidone therapy on gastrointestinal symptoms, gastric emptying and quality of life in patients with gastroparesis. Am J Gastroenterol 1997;92(6):976-980

14. Maddern GJ. Galactorrhoea due to domperidone. Med J Aust 1983;2(11):539-540

15. Lutke Farwick J, van Laar T, Bruggeman R, Leenders K. Domperidoneinduced reversible hyperprolactinemia and sexual dysfunctioning in a patient with Parkinson's disease: a case report [abstract]. Mov Disord 2002;17 Suppl 5:105.

16. Franckx J, Noel P. Acute extrapyramidal dysfunction after domperidone administration. Report of a case. Helv Paediatr Acta 1984; 39(3):285-288.

17. Biasini A, Alberti A. Extrapyramidal dysfunction after domperidone [letter]. Helv Paediatr Acta 1985;40(1):93-94.

18. Shafrir Y, Levy Y, Ben-Amitai D, Nitzan M, Steinherz R. Oculogyric crisis due to domperidone therapy [letter]. Helv Paediatr Acta 1985;40(1):95
19. Van Der Steen M, Du Caju MVL, Van Acker KJ. Gynaecomastia in a male infant given domperidone. Lancet 1982;2(8303):884-885.

Eva Cho, BScPharm, ACPR, is with the Pharmacy, Children's and Women's Health Centre of British Columbia, Vancouver, British Columbia.

Sharon Ho, BSCPhm, ACPR, is with the Pharmacy, Children's and Women's Health Centre of British Columbia, Vancouver, British Columbia.

Patricia Gerber, BScPharm, PharmD, FCSHP, is with the Faculty of Pharmaceutical Sciences, University of British Columbia, Vancouver, British Columbia.

A George F Davidson, BSC, MD, FRCPC, is with the Cystic Fibrosis Clinic, Children's and Women's Health Centre of British Columbia, Vancouver, British Columbia.

\section{Address correspondence to:}

Eva Cho

Pharmacy

Children's and Women's Health Centre of British Columbia 4480 Oak Street

Vancouver $\mathrm{BC}$

V6H 3V4

e-mail: echo2@cw.bc.ca 